\title{
Effect of Pressure/Heat Combinations on Blue Whiting (Micromesistius poutassou) Washed Mince: Thermal and Mechanical Properties
}

Fernando Fernández-Martín*, Miriam Pérez-Mateos, and Pilar Montero

Instituto del Frío (CSIC), Ciudad Universitaria, E-28040 Madrid, Spain

\section{Abstract}

Washed ground muscle of blue whiting was comminuted at low ionic strength and low temperature, and the batter was subjected to different pressure/heat processings. The functionality induced in the combined processed gels was evaluated by water holding and several rheological and fracture properties and compared to that obtained for traditional heatinduced gel. Ultrastructure was viewed by scanning electron microscopy. Protein denaturation was assessed by differential scanning calorimetry (DSC), and the thermal behavior of pressurized gels revealed that pressure and temperature were interdependent. At nondenaturing temperatures, the higher the pressure, the larger was the protein unfolding effect. At denaturing temperatures, pressure prevented fish protein from subsequent thermal denaturation. DSC demonstrated that pressurized samples underwent both types of pressure effects at the same time. It transmitted a mixed character to the pressure-induced gels, which displayed a rheological behavior intermediate between cold-set and heat-set gels.

Keywords: High pressure/thermal treatments; cold gelation; heat gelation; blue whiting (Micromesistius poutassou) washed mince; protein denaturation; mechanical properties; ultrastructure; DSC; TPA; SEM 


\section{Introduction}

Gelation of muscle-based foods has traditionally been considered as a thermally induced process until it was shown that high-pressure treatments can contribute to protein gel networking. In general, high-pressure/low-temperature treatments of washed fish mince yield gels that are softer and more elastic than gels obtained by traditional heating at atmospheric pressure (Okamoto et al., 1990; Chung et al., 1994; Carlez et al., 1995; Pérez-Mateos and Montero, 1997). Some authors (Ko et al., 1990; Ishikawa et al., 1991) have reported advantages of using hydrostatic pressurization and heating combinations for gelling washed sardine meat pastes, specifically those with low gel-forming ability (Pérez-Mateos and Montero, 1997). In some fish species such as blue whiting, heat-induced gelation at atmospheric pressure is normally carried out in two steps (Niwa, 1992): the batter (sol) is treated at $37^{\circ} \mathrm{C}$ for 30 min, or at a lower temperature for a longer time $\left(4-7^{\circ} \mathrm{C}\right.$ overnight), so that it sets into an elastic and translucent gel (suwari). This gel is further heated to $>80{ }^{\circ} \mathrm{C}$ to produce a stable gel (kamaboko), which is stronger, more opaque, and more elastic than the gel produced in the case of single-step heating.

Gelling is a complex process that starts with the conditioning of the proteins involved through introduction of certain conformational changes (protein unfolding) in their structure. Iso et al. (1994) reported that carp meat pressurization at $200 \mathrm{MPa}$ and $0-5{ }^{\circ} \mathrm{C}$ for $13 \mathrm{~h}$ produced a denaturation mechanism similar to that produced by heating alone at $90{ }^{\circ} \mathrm{C}$. However, the real conclusion of their work was that both kinds of treatments were similar in terms of energetics. Ko et al. (1990) observed Mg-ATPase activity in sardine actomyosin after pressure treatments and concluded that pressure-induced protein denaturation is very different from thermal denaturation. Fernández-Martín et al. (1997) have recently reported that final denaturing effects in pressure/heat processing of pork meat batters were pressure-temperature interdependent: pressure, depending on the level, produced major protein denaturation when applied at nondenaturing temperatures; conversely, pressure prevented subsequent protein thermal denaturation at denaturing temperatures. This kind of complex behavior is known to be a 
consequence of the elliptic form that the typical pressure-temperature phase diagram of a protein presents. In correspondence to this high-pressure denaturation there exists a low pressure that will also cause protein denaturation at the same temperature. This is similar to the two corresponding temperatures for the thermal denaturation at a given pressure, that is, cold and heat denaturations.

The chief aim of this work was to ascertain the differences that combined pressure/heat gelling processes may make to blue whiting washed mince by tracking its thermal response in the course of processing using differential scanning calorimetry (DSC). The functionality induced in the gels was assessed by determining their water-binding capacity and various different textural attributes derived from both subjective and objective mechanical tests. Ultrastructural aspects were also dealt with to seek any link between structure and gel-inducing method. On the basis of previous experience (Pérez-Mateos et al., 1997), two pressure/heat combinations will be studied: $200 \mathrm{MPa}$ at $7{ }^{\circ} \mathrm{C}$ for $10 \mathrm{~min}$ and $375 \mathrm{MPa}$ at $37^{\circ} \mathrm{C}$ for $20 \mathrm{~min}$. The two corresponding thermal samples at 7 and $37^{\circ} \mathrm{C}$ were prepared and used for comparative purposes. A heatinduced gel produced by a two-step process $\left(37^{\circ} \mathrm{C} / 30 \mathrm{~min}\right.$ followed by $90{ }^{\circ} \mathrm{C} / 50 \mathrm{~min}$ ) was chosen as the traditional, stable product for reference.

\section{Materials and Methods}

Washed Mince. Blue whiting (Micromesistius poutassou Risso) was caught off the Cantabrian coast in May 1997. Average size was $20.8 \pm 1.0 \mathrm{~cm}$ and average weight $78.0 \pm 8.5 \mathrm{~g}$. Fish were headed, gutted, and washed. Skin and bones were removed with a deboning machine (Baader 694, Lübeck, Germany). Muscle was ground ( $3 \mathrm{~mm}$ o.d.) and washed in $0.2 \% \mathrm{NaCl}$ solution at $\sim 3{ }^{\circ} \mathrm{C}$ (solution/muscle $=3: 1$ ) with constant stirring for $10 \mathrm{~min}$, and after decanting, excess water was removed by a screw press (Baader 523). The washed mince, with $4 \%$ sorbitol and $0.2 \%$ tripolyphosphate (TPP) added as cryoprotectants, was immediately vacuum-packed in bags (Cryovac BB-1, Barcelona, Spain) and frozen to $-30{ }^{\circ} \mathrm{C}$ in a plate freezer (Saabroe SMC, Denmark). The bags were stored at $-80^{\circ} \mathrm{C}$ in a vertical freezer cabinet (Revco ULT, Revco 
Scientific Inc., Asheville, NC) to minimize alteration during frozen storage. Main constituents were analyzed according to AOAC (1984) procedures; crude fat was analyzed according to the method of Bligh and Dyer (1959). Protein functionality was assessed by soluble protein content, viscosity, and water-holding capacity (WHC). Protein solubility was determined according to the method of Ironside and Love (1958): Washed mince was homogenized in 5\% $\mathrm{NaCl}$ solution for 1 min at high speed (position 7; Omnimixer, Ivan Sorvall Inc., Norwalk, CT) and centrifuged for 30 min at $0-5{ }^{\circ} \mathrm{C}$ and $3000 \mathrm{~g}$ (Sorvall RT6000B, DuPont Co., Wilmington, DE). Supernatant was precipitated by addition of $60 \%$ trichloroacetic acid and centrifuging at $3000 \mathrm{~g}$ for $15 \mathrm{~min}$. Soluble protein was determined in duplicate by using the Kjeldahl method in the pellet. Apparent viscosity was determined in triplicate on a homogenate (mince/water $=1: 4$ ) at $3-5{ }^{\circ} \mathrm{C}$ by a Brookfield-LV viscometer (Brookfield Engineering NABS, Stoughton, MA) following 3 min with the rotor at $12 \mathrm{rpm}$ (Borderías et al., 1985).

Connective proteins ( $\sim 1.6 \%$ total protein, essentially collagen) were obtained after washed mince protein solubilization by successive treatments with dilute $\mathrm{NaCl}$ solutions (Borderias and Montero, 1985).

Batter Preparation. Frozen washed mince (1 month old) was semithawed and placed in a refrigerated $\left(<10^{\circ} \mathrm{C}\right)$ vacuum homogenizer (Stephan UM5, Stephan u. Söhne GmbH \& Co., Germany) and ground for $1 \mathrm{~min}$ at $\sim 3000 \mathrm{rpm}$ (start II position). Sodium chloride (1\% w/w) and crushed ice to give the required final moisture (80\%) were added, and homogenization was then restarted at $\sim 1500 \mathrm{rpm}$ (start I) in a vacuum for $6 \mathrm{~min}$. The resulting batters were stuffed into cases (Krehalon Soplaril, Barcelona, Spain) of $40 \mu \mathrm{m}$ thickness and $3.5 \mathrm{~cm}$ diameter and processed.

Gel Preparation. High-Pressure/Heat Combinations. Filled casings were placed in the vessel (containing water - as pressure transmitter - thermostated at the processing temperature) of a high-pressure pilot unit (ACB 665, Gec Alsthom, Nantes, France) and subjected to either of two pressure/temperature/time combinations: (L, $200 \mathrm{MPa} / 7^{\circ} \mathrm{C} / 10 \mathrm{~min} ; \mathrm{H}, 375 \mathrm{MPa} / 37^{\circ} \mathrm{C} / 20 \mathrm{~min}$ ). Thermal Processes. The treatments by immersion in a water bath were as follows: $\mathrm{S} 1,7^{\circ} \mathrm{C} / 10$ min; and S2, $37^{\circ} \mathrm{C} / 20 \mathrm{~min}$, as the temperature-time combinations used in pressurization $\mathrm{L}$ and 
$\mathrm{H}$; cooking $\mathrm{T}\left(37^{\circ} \mathrm{C} / 30 \mathrm{~min}+90^{\circ} \mathrm{C} / 50 \mathrm{~min}\right)$ and its first step $\mathrm{T} 1\left(37^{\circ} \mathrm{C} / 30 \mathrm{~min}\right)$. All of the samples were cooled immediately after processing and stored in a cold room at $\sim 4{ }^{\circ} \mathrm{C}$ for immediate analysis ("fresh" samples hereinafter). All of them except T1 were analyzed again after $24 \mathrm{~h}$ of holding in the cold room ("aged" samples). In summary, S2 and T1 constituted setting processes yielding the respective suwari S2 and T1 gels. Aging $\left(4^{\circ} \mathrm{C} / 24 \mathrm{~h}\right)$ was an additional setting process for the corresponding samples, S1 aged sample thus being suwari S1 gel. T, the reference two-step heating treatment, was a cooking-after-setting process.

DSC. A Perkin-Elmer differential scanning calorimeter DSC7 (Norwalk, CT) was used, previously calibrated for temperature (melting points of gallium and benzoic acid) and energy (indium fusion enthalpy). Samples of $\sim 15 \mathrm{mg}( \pm 0.002 \mathrm{mg})$ weighed by an electronic balance Perkin-Elmer AD4 were capsulated in aluminum pans and hermetically sealed. Four to six samples of each class were scanned from 5 to $90^{\circ} \mathrm{C}$ at $10^{\circ} \mathrm{C} / \mathrm{min}$ under dry nitrogen purge of $30 \mathrm{~mL} / \mathrm{min}$, and a second heating was scanned to check that all proteins had already been irreversibly denatured in the first. After DSC evaluation, every capsule (with pinhole in the cover) was heated to $105{ }^{\circ} \mathrm{C}$ for dry matter determination. Temperatures $\left(t,{ }^{\circ} \mathrm{C}\right)$ and enthalpies $(\Delta H$, $\mathrm{J} / \mathrm{g}$ ), integrated as outlined in Figure $1 \mathrm{~A}$ but with the baseline smoothed to a third-degree polynomial, were determined to better than $0.8^{\circ} \mathrm{C}$ and $8 \%$, respectively.

WHC. According to Montero and Gómez-Guillén (1996), $1.5 \mathrm{~g}$ of sample was placed in a centrifuge tube along with two Gilson Pipetman dried pipet filters and centrifuged (Sorvall RT6000B) at $4000 \mathrm{~g}$ for $15 \mathrm{~min}$ at ambient temperature. WHC was expressed as water retained per $100 \mathrm{~g}$ of water present in the sample prior to centrifuging. All determinations were carried out in triplicate.

Textural Assessment. Samples (3.5 cm o.d.) were removed from their casings, cut into pieces (3 $\mathrm{mm}$ or $3 \mathrm{~cm}$ height), and tempered at $20^{\circ} \mathrm{C}$ for analysis. Samples were put through (at least in quadruplicate) a subjective folding test, and several objective determinations (Bourne, 1982) were performed with an Instron 4501 (Instron Engineering Corp., Canton, MA). 
Folding Test. This test, the only one using $3 \mathrm{~mm}$ slices, was carried out according to the method of Suzuki (1981) to score samples from 1 (crumbling) to 5 (no cracking when folded into quadrants).

Penetration Test. The samples were penetrated to breaking point with a round-ended stainless steel cylindrical plunger ( $5 \mathrm{~mm}$ o.d.) connected to a $100 \mathrm{~N}$ load cell, at a cross-head speed of 10 $\mathrm{mm} / \mathrm{min}$. Breaking force (BF, N), breaking deformation (BD, $\mathrm{mm}$ ), and work of penetration (WP, J) were determined from the corresponding force-deformation curves.

Stress/Relaxation Test. This test was carried out with a flat-headed cylindrical stainless steel plunger (58 $\mathrm{mm}$ o.d.) connected to a $5 \mathrm{kN}$ load cell. A constant deformation rate of $50 \mathrm{~mm} / \mathrm{min}$ was applied in uniaxial compression up to 60\% sample deformation (cracking avoided), and the reaction force was then recorded for $1 \mathrm{~min}$. Relative relaxation was calculated by $Y=\left(F_{0}-\right.$ $\left.F_{\mathrm{e}}\right) / F_{\mathrm{o}}$ as a function of the forces registered at the onset $\left(F_{\mathrm{o}}\right)$ and the end $\left(F_{\mathrm{e}}\right)$ of the relaxation period. $E=100-(Y / 100)$ was taken as an elasticity index (\%).

Texture Profile Analysis (TPA). The samples were compressed in the same conditions as before but in two uninterrupted cycles (Bourne, 1982). The parameters read off the TPA curves were hardness $(\mathrm{Hd}, \mathrm{N})$ as the maximum force in the first compression, adhesiveness $(\mathrm{Ad}, \mathrm{kJ})$ as the work needed to bring the cross-head to its initial position for the second compression (negative area of the force-deformation diagram between compression cycles), and cohesiveness (Ch, dimensionless) as the positive areas ratio of second to first compression.

Scanning Electron Microscopy (SEM). Cubes of 2-3 mm sides were cut from inside the gels, fixed by $2 \%$ glutaraldehyde in phosphate buffer $(\mathrm{pH} 7.3)$, and dehydrated in increasing concentrations of acetone (from 40 to 100\%). The samples were then critical-point dried with $\mathrm{CO}_{2}$ as transition fluid in a dryer (Balzer, CPD030, Liechtenstein), mounted on copper sample holders, and sputter-coated with gold in a metallizer (Balzer, SCD004). Samples were kept in a dryer until examination at $20 \mathrm{kV}$ (JEOL, JSC 6400, Japan).

Statistical Analysis. One-way analysis of variance was carried out using the Statgraphics package (STSC Inc., Rockville, MD). Differences between means of pairs were resolved by an LSD range test. Significance level was $P<0.05$. 


\section{Results}

Washed Mince and Batter Characterization. The main composition of the washed mince 13.3 \pm 0.2 protein, $0.40 \pm 0.04$ fat, $0.65 \pm 0.03$ ash, and $80.3 \pm 0.3$ water (data in percent) plus $4.2 \%$ cryoprotectant. The original protein functionality was considered good according to the results: $6.133 \pm 67$ cP viscosity; $33.8 \pm 0.4 \%$ soluble protein; $76.6 \pm 1.1 \%$ WHC.

Figure $1 \mathrm{~A}$ shows the DSC trace of the recently frozen washed mince as a typical curve of myofibrillar fish muscle proteins depleted of sarcoplasmic and stroma components. It consisted of two zones of sharp endothermal effects separated by a mark around $60{ }^{\circ} \mathrm{C}$ : the first zone (I) presented a main peak at $46.5{ }^{\circ} \mathrm{C}$ of maximum temperature between two small, less defined events at about 36.5 and $56.1^{\circ} \mathrm{C}$; the second zone (II) presented a single large peak at $74.7^{\circ} \mathrm{C}$. The DSC trace extended throughout the $22.5-81{ }^{\circ} \mathrm{C}$ temperature interval, although a minor effect was also visible $\sim 88{ }^{\circ} \mathrm{C}$, and the associated enthalpy, $18.4 \mathrm{~J} / \mathrm{g}$ (referred hereinafter to protein content), was roughly distributed 74:26 in both zones. Figure 1B shows the typical DSC trace of connective protein extract, which consisted of a single broad transition at $45.5{ }^{\circ} \mathrm{C}$ maximum temperature (moisture $>70 \%$; otherwise, two transitions appeared at $\sim 35$ and 48.5 ${ }^{\circ} \mathrm{C}$ ) with a melting enthalpy of $23.1 \mathrm{~J} / \mathrm{g}$. Figure $1 \mathrm{C}$ reflects the first stage (pregrinding) of batter preparation, which induced minor changes in the profile and a small reduction in enthalpy (7\%). The second stage (comminuting and salt blending) introduced major changes (Figure 1D) as evidenced by the diffuse profile of the peaks and some protein destabilization, mainly in zone I with $3-5.5{ }^{\circ} \mathrm{C}$ downward temperature shifting, and much lower in zone II $\left(<1{ }^{\circ} \mathrm{C}\right)$. There was a major reduction of enthalpy change, $\sim 16 \%(15.6 \mathrm{~J} / \mathrm{g})$, but the distribution between zones remained unaltered.

Thermal Behavior of Processed Products. Figure 1E shows the thermal behavior of batter treated at $37^{\circ} \mathrm{C}$ for 30 min (first cooking step, sample T1). Important changes occurred in zone I (mainly the first half), while II was unaltered: the lower integration temperature increased (30 $\left.{ }^{\circ} \mathrm{C}\right)$ and the enthalpy change decreased $\sim 37 \%(6.8 \mathrm{~J} / \mathrm{g})$ with respect to the batter, with a new 
distribution of $52: 48$. The second cooking step at $90{ }^{\circ} \mathrm{C}$ for $50 \mathrm{~min}$ (sample T) produced complete denaturation (DSC rescan superposing) of the protein matrix as shown in the DSC "flat" response of Figure $1 \mathrm{~F}$, where the only noticeable event was a slope change at $\sim 45^{\circ} \mathrm{C}$.

When batter was subjected to high-pressure/heat combinations, the resulting products exhibited the thermal patterns shown in Figures 2 and 3. These present (more sensitively) the corresponding sample DSC curves after baseline subtraction. Sample $\mathrm{S} 1\left(7^{\circ} \mathrm{C} / 10 \mathrm{~min}\right)$ is shown in Figure $2 \mathrm{~A}$ (similar to Figure 1D): transition temperatures at about 34,45 , and $51^{\circ} \mathrm{C}$ in zone I, and about $75^{\circ} \mathrm{C}$ in zone II, with associated enthalpy of $15.8 \mathrm{~J} / \mathrm{g}$ distributed 74:26. Product processed by combination $\mathrm{L}\left(200 \mathrm{MPa} / 7^{\circ} \mathrm{C} / 10 \mathrm{~min}\right)$ presented the same transition temperatures as S1 (Figure 2B), but there was a large reduction in areas below the peaks at about 45 and $75{ }^{\circ} \mathrm{C}(\Delta H=10.8 \mathrm{~J} / \mathrm{g})$, followed by a new distribution between zones (81:19). Product processed by combination $\mathrm{H}\left(375 \mathrm{MPa} / 37^{\circ} \mathrm{C} / 20 \mathrm{~min}\right.$ ) showed a DSC profile (Figure $3 B$ ) resembling the first zone of sample $L$ in both shape and size, especially in the main transition at $\sim 45^{\circ} \mathrm{C}$; however, the major difference was found in the total absence of response in zone II, with a decrease in enthalpy change of $\sim 33 \%$ with respect to the lower pressurized sample $L(8.4 \mathrm{~J} / \mathrm{g})$. Figure 3A shows the DSC trace of sample S2, the batter heated alone in the same thermal treatment $\left(37^{\circ} \mathrm{C} / 20 \mathrm{~min}\right)$ as sample $\mathrm{H}$. This was very similar in profile to Figure $1 \mathrm{E}$ (peaks at 45 and $51^{\circ} \mathrm{C}$ ), but the associated enthalpy was naturally somewhat higher (7.3 $\mathrm{J} / \mathrm{g})$

Aging for $24 \mathrm{~h}$ in the cold room yielded small increases $(<10 \%)$ in DSC trace and area. The greatest changes occurred in S1 and both pressurized products $\mathrm{L}$ and $\mathrm{H}$.

Gel Functionality. WHC was quite high in all cases, as shown in Table 1; the significantly lowest value was found in heat-induced gel $\mathrm{T}$. The rest of the data were not significantly different.

All of the samples, either freshly prepared or after $4{ }^{\circ} \mathrm{C} / 24 \mathrm{~h}$ aging, scored maximum values in the folding test except S1-fresh, which scored the minimum. The samples were more sensitive 
to the elasticity index $E$ (Table 2) but S1-fresh was unsuitable for evaluation; gels $\mathrm{H}$ and $\mathrm{L}$ yielded the significantly highest and lowest values, respectively. Aging reduced $E$ significantly in all samples except in gel $\mathrm{T}$, which remained practically unaltered with a medium score. Gel S1 was the significantly highest in $E$, but the others in the series maintained the same order as in fresh samples.

Table 3 shows data obtained in penetration tests. Gel T required the significantly highest breaking force (BF) to yield the significantly lowest breaking deformation (BD), in contrast to gel $\mathrm{L}$, for which the opposite was true. The behavior of gel $\mathrm{H}$ was intermediate between gels $\mathrm{T}$ and S2 for both parameters. Aging produced minor increases of BF values except in pressurized gels, for which these values were high, particularly in gel $L$ which required the significantly highest BF. Gel H remained intermediate between gels T and S2. Thermal gels S2 and S1 gave the lowest BF values. Aging, on the other hand, did not alter the relative behavior of deformation BD in gels. With regard to work of penetration (WP), the situation was much more complex: in general, thermal gels S2 and T exhibited the significantly highest values when fresh but the lowest (S1 the last) when aged. The behavior of gel T was intermediate in both kinds of sample. Pressurized gel $L$ gave the significantly highest score, followed by (not significantly different) gels $\mathrm{H}$ and $\mathrm{T}$.

Regarding TPA parameters (Table 4), the general behavior was the same in both fresh and aged samples; variations were not significant in thermal gels but were so in pressurized gels. In hardness $(\mathrm{Hd})$ and adhesiveness ( $\mathrm{Ad}$ ) evaluations, gel T gave the significantly highest scores, whereas the other thermal gels (S2 and S1) generally gave the significantly lowest values. Again, pressurized gels were more prone to aging than any other and gel $\mathrm{H}$ was once more close to thermal gels S2 or T. With respect to cohesiveness (Ch), gel T gave the second lowest values (after gels $\mathrm{H}$-fresh and $\mathrm{S} 1$-aged, respectively), whereas gel $\mathrm{L}$ gave the significantly highest value followed by gel S2 in both kinds of sample. 


\section{DISCUSSION}

Thermal Properties. The DSC zone I of blue whiting washed mince, either recently prepared or thawed after frozen storage (Figure 1C), reflects the thermal denaturation of myosin and collagen (plus minor connective proteins). Myosin thermal denaturation is known to occur on several structural domains capable of undergoing independent cooperative transitions (Privalov, 1982), depending on biological source (animal, species) and experimental environment ( $\mathrm{pH}$, ionic strength). In Figure 2A, the following transitions are assigned to myosin: (subfragment S1) at $33.5^{\circ} \mathrm{C}$ (shoulder $\sim 29^{\circ} \mathrm{C}$ ) and (rod) at $44.5^{\circ} \mathrm{C}$ (Figure $2 \mathrm{C}$ ) and $51{ }^{\circ} \mathrm{C}$. Transition at $44.5^{\circ} \mathrm{C}$ was also due to collagen (Figure 1B). Zone II reflects the thermal response of actin at $74.7^{\circ} \mathrm{C}$, which may also be responsible for the minor event at the highest temperatures (F-actin). Thermal results were difficult to compare given the scarcity of precedents concerning other fish species in the literature (Hastings et al., 1985; Poulter et al., 1985; Davies et al., 1988; Park and Lanier, 1989; Howell et al., 1991; Paredi et al., 1994). In general, temperatures and enthalpies were more similar to those reported for hake (Beas et al., 1990, 1991), possibly because of similarities in fish habits and environments.

Despite $0.2 \%$ TPP (sorbitol cryoprotecting fortifier but also $\mathrm{NaCl}$ replacer for actomyosin dissociation; Tokunaga and Nishicka, 1987), the low salt concentration ( $<0.2 \mathrm{M})$ produced only a moderate instability effect, which has also been reported in other fish species, for example, tilapia (tropical waters) by Park and Lanier (1989) or cod (cold marine waters) by Hastings et al. (1985) and Davies et al. (1994). The DSC profile in Figure 2A illustrates the suitability of a twostep cooking process for washed blue whiting muscle comminuted at low ionic strength, for example, heating at $\sim 40^{\circ} \mathrm{C}$ followed by heating at $>80^{\circ} \mathrm{C}$.

Pressurized gels underwent some hysteresis after aging; protein denaturation by pressure may be reversible to some extent (Mozhaev et al., 1996) in opposition to the irreversible thermal denaturation (gel T). Both pressurized gels exhibited a similar thermal pattern at zone I, related to myosin and collagen (Figures $2 \mathrm{~B}$ and $3 \mathrm{~B}$ ). The transition with midpoint $\sim 45^{\circ} \mathrm{C}$ corresponded 
partially to collagen (which would remain unaltered since its hydrogen-bonded helical structure would be strengthened by pressure), but mainly to myosin. In fact, the partial areas below the $45{ }^{\circ} \mathrm{C}$ peak amounted to roughly $2.5 \mathrm{~J}$ in the two DSC traces of samples $\mathrm{L}$ and $\mathrm{H}$, a much higher figure than had been estimated $(0.4 \mathrm{~J})$ as the contribution of the collagen content $(\sim 0.2 \%)$ of the gels. With regard to the actin component, both combinations promoted dissociation (F-actin disappeared; Ikeuchi et al., 1992) and denaturation (partial at the lower pressure but total at the higher level). Interesting analyses emerged from comparisons between pressurized gels $\mathrm{L}$ and $\mathrm{H}$ and the corresponding thermal gels S1 and S2 (Figures 2C and 3C, respectively). Downward-plotted curve domains had a negative sign and represented the protein denaturing effect of pressure/heat processing over the thermal-only treatment. Conversely, upward domains had a positive sign and represented the effect of preserving protein denaturation over the corresponding thermal-only treatment. At $7{ }^{\circ} \mathrm{C}$, a nondenaturing temperature for the batter proteins (Figure 2A), $200 \mathrm{MPa}$ hydrostatic pressure caused partial denaturation at both zones I and II (Figure 2C), specifically on the $45{ }^{\circ} \mathrm{C}$ transition domain of myosin rod and on actin. At $37^{\circ} \mathrm{C}$, a temperature that is partially denaturing in myosin and collagen but nondenaturing in actin (Figure 3A), $375 \mathrm{MPa}$ hydrostatic pressure successfully protected both myosin and collagen from subsequent thermal denaturation but produced complete denaturation of actin (Figure 3C). The net denaturing effect of combination $\mathrm{H}$ over the initial batter is depicted in Figure 3D, in which myosin unfolding is slightly greater (at the extreme transitions) and better outlined (transitions at $\sim 35,45$, and $51^{\circ} \mathrm{C}$ ) than in combination $\mathrm{L}$ (Figure 2C).

These data confirm previous results on pork meat batters (Fernández-Martín et al., 1997). These authors explained the antagonistic effects that mechanical- and thermal-driving forces may originate with regard to protein denaturation in these types of pressure/heat processing, where pressure is applied (uniformly and instantaneously transmitted) at a certain temperature (anisotropically and slowly succeeding). 
Mechanical Properties. Suwari S1 gel obtained by (endogenous transglutaminase-induced) cold setting $\left(4^{\circ} \mathrm{C} / 24 \mathrm{~h}\right)$ of S1-fresh $\left(7^{\circ} \mathrm{C} / 10 \mathrm{~min}\right)$ was an entirely different product in that proteins did not undergo thermal unfolding, yielding the lowest scores in penetration parameters, $\mathrm{Hd}$ and $\mathrm{Ch}$, as well as the maximum elasticity E. According to Hermansson et al. (1986), bovine myosin in solution at $4{ }^{\circ} \mathrm{C}$ may undergo cold gelation at certain $\mathrm{pH}$ values and ionic strengths, yielding a structure of fine strands made up of myosin filaments formed during low-temperature incubation. Sompongse et al. (1996) concluded that during ice storage carp actomyosin underwent disulfide bonding with formation of myosin heavy chain dimers by oxidation of SH groups on myosin rods. Niwa et al. (1992), Montero and Gómez-Guillén (1996), and Montero et al. (1997), reported that hydrogen bonds seem to play some role in the stabilization of the network structure of cooled fish washed mince gels.

Suwari S2 gel ( $\left.37^{\circ} \mathrm{C} / 20 \mathrm{~min}\right)$ exhibited partial denaturation of myosin and rheological behavior intermediate between those of pressurized $\mathrm{L}$ and $\mathrm{H}$ aged gels. This kind of elastic gel has been described by Roussel and Cheftel (1990) in the case of sardine surimi at $37^{\circ} \mathrm{C} / 30 \mathrm{~min}$. The setting produced intermolecular SH/SS exchange, calcium-protein electrostatic attractions, and hydrophobic interactions. According to these authors the gel network was mainly due to crosslinking of myosin heavy chains that have been wholly solubilized and probably unfolded in the presence of $\mathrm{NaCl}$. It seems (Figures $1 \mathrm{E}$ and $3 \mathrm{~A}$ versus Figure $2 \mathrm{~A}$ ) that unfolding was partial and thermal because some myosin molecular domains are already sensitive to this temperature.

Gel T, obtained by partial thermal denaturation of myosin and collagen in the first step T1 (Figure 1E) followed by denaturation of the total protein matrix in the second (Figure 1F; glass transition at $\sim 45^{\circ} \mathrm{C}$ ), would have high covalent SS cross-linking (Pérez-Mateos et al., 1997). The time-dependent myosin head association would be favored by the first heating step, and the final cooking step could benefit both myosin tail networking and actin aggregation. This could therefore be the best gelling process to induce the desired overall functional properties (sufficiently high WHC, relatively high $\mathrm{BF}$ and $\mathrm{Hd}$, as well as $\mathrm{Ad}$, medium $E$ and $\mathrm{WP}$, and relatively low $\mathrm{BD}$ and $\mathrm{Ch}$ ) in as stable a product as possible. 
Pressurized gels $L$ and, to a lesser extent, $H$, changed considerably with aging in contrast to the highly stable thermally set gel $\mathrm{T}$, mainly in parameters WP, $\mathrm{Hd}$, and Ad, which increased significantly, clearly indicating considerable restructuring. According to several authors (Yamamoto, 1990; Shoji et al., 1994; King et al., 1994), hydrostatic pressure may dissociate myosin at low ionic strength into the two $\alpha$-helix chains, which may aggregate in different ways from the original moiety after pressure release. On the basis of a hypothesis suggested by others, Gilleland et al. (1997) reported that setting at $25^{\circ} \mathrm{C} / 120 \mathrm{~min}$ after $300 \mathrm{MPa} / 5^{\circ} \mathrm{C} / 30 \mathrm{~min}$ pressurization of surimi pastes produced synergistic effects (pressure and transglutaminase, with disulfide bond formation) on the gels strength. Carlez et al. (1995), on threadfin bream, and Pérez-Mateos et al. (1997), on blue whiting, found a high percentage of ionic and hydrogen bonds in pressure-induced (300 and $200 \mathrm{MPa}$ ) gels at low temperature $\left(3\right.$ and $10{ }^{\circ} \mathrm{C}$, respectively). All of these facts clearly indicate that the effect of pressure and its attendant mechanisms predominate over protein thermal denaturation in these types of pressure/heat treatments. Consequently, these combined processes may induce different gelling functionality in the system and lead to final products with characteristics (WHC, texture) different from those produced by heating alone.

Mixing Mechanism. DSC revealed that whatever the different processing parameters, $L$ (lowest pressure and temperature, Figure $2 \mathrm{~B}$ ) and $\mathrm{H}$ (highest pressure and temperature, Figure $3 \mathrm{~B}$ ) combined treatments converged in that the pressurized gels had practically identical myosin characteristics (the main gelling protein), diverging only in the extent of unfolded actin. We may then speculate as to a mixing mechanism for the structure of pressure-induced (cold-setting susceptible) gels: filamentous, largely folded myosin single chains would aggregate in strands to form the bearing gel network (as in cold gelation), and unfolded globular actin would aggregate corpuscularly, thus weakening the net to some extent (as in heat gelation). It is consistent with data from some of the authors cited above and would help to explain the relative rheological behavior of pressurized gels, that is, why gel $L$ had higher $B F, W P, H d$, and $C h$ than gel H. Gel L further exhibited a DSC pattern intermediate between those of suwari gels S1(not 
denatured) and S2 (denatured); at the same time, it was rheologically unrelated to S1 but strongly related to $\mathrm{S} 2$, particularly in $E, \mathrm{BD}$, and $\mathrm{Ad}$. Gel $\mathrm{H}$ was very peculiar in that its DSC trace was also intermediate between those of S1 and S2 (zone I) but close to T as well (zone II). It seems likely that this complex thermal behavior would account for the systematic similarity between the rheological behavior of gel $\mathrm{H}$ and that of the nonpressurized gels, particularly suwari S1 and kamaboko T. In fact, gel $\mathrm{H}$ was close to gel S1 in elasticity $(E)$ and adhesiveness (Ad), but close to gel $\mathrm{T}$ in penetration parameters, hardness $(\mathrm{Hd})$ and cohesiveness $(\mathrm{Ch}) . \mathrm{Gel} \mathrm{H}$ seemingly shared the most characteristic rheological indices of both types of cold-set and heatinduced gel. Thus, DSC and the mixing mechanism would also help to explain the rheology of pressurized gels with respect to nonpressurized gels.

Figure $4 \mathrm{~A}$ is an SEM image of gel $\mathrm{L}$ showing a very dense or compact matrix coherent with the fact that $L$ scored highest in penetration test (Burgarella et al., 1985) and cohesiveness. The structure of gel T (Figure 4C) was relatively less compact, as evidenced by irregularly distributed vacuoles, which was consistent with relatively lower mechanical parameters. Gel H (Figure 4B) clearly shared both aspects in that it had a more compact matrix than gel $\mathrm{T}$ but a more porous structure than gel $\mathrm{L}$, in coherence with its intermediate rheological behavior. Although a more detailed discussion would require TEM, the SEM ultrastructure micrographs seem likely to support the view of the mixing mechanism above formulated.

\section{General Conclusions}

This work confirms previous results on pork meat batters (Fernández-Martín et al., 1997) in that, due to the predominance of pressure-driven over temperature-driven mechanisms, pressure/heat combinations may produce two types of effect on the protein matrix of blue whiting washed mince. At nondenaturing temperatures, pressure caused denaturation of fish 
batter proteins, with greater effect the higher the level. At per-se denaturing temperatures, however, pressure preserved fish batter proteins from subsequent thermal denaturation. Interestingly, because of the different myosin and actin thermal stabilities in the system, each of the pressurized samples underwent both opposite types of pressure effect simultaneously. Myosin (and/or its heavy chain fragments) was strongly preserved in undenatured conditions, whereas actin was severely unfolded; this lent pressure-induced gels ( $\mathrm{H}$ in particular) a "mixed" character, that is, some macroscopic and microscopic attributes intermediate between those characteristic of cold-set and heat-induced gelation.

\section{Acknowledgment}

We gratefully acknowledge M. Solas (Dpto. Biología Celular, Fac. C. Biológicas, UCM) for performing the micrography.

\section{REFERENCES}

1. AOAC. Official Methods of Analysis, 12th ed.; Association of Official Analytical Chemists: Washington, DC, 1984.

2. Beas, V. E.; Wagner, J. R.; Crupkin, M.; Añon, M. A. Thermal denaturation of hake (Merluccius hubbsi) myofibrillar proteins. A differential scanning calorimetric and electrophoretic study. J. Food Sci. 1990, 55, 683-687, 696.

3. Beas, V. E.; Wagner, J. R.; Añon, M. A.; Crupkin, M. Thermal denaturation in fish muscle proteins during gelling: Effect of spawning condition. J. Food Sci. 1991, 56, 281-284.

4. Bligh, E. G.; Dyer, W. J. A rapid method of total lipid extraction and purification. Can. J. Biochem. Phys. 1959, 37, 911-917. 
5. Borderías, A. J.; Montero, P. Changes in fish muscle collagen during frozen storage. In Storage Lives of Chilled and Frozen Fish and Fish Products; International Institute of Refrigeration; Aberdeen, U.K., 1985; pp 85-91.

6. Borderías, A. J.; Jiménez Colmenero, F.; Tejada, M. Parameters affecting viscosity as a quality control for frozen fish. Mar. Fish. Rev. 1985, 47, 31-42.

7. Bourne, M. C. Principles of objective texture measurement. In Food Texture and Viscosity: Concept and Measurement; Academic Press: New York, 1982; pp 45-117.

8. Burgarella, J. C.; Lanier, T. C.; Hamann, D. D.; Wu, M. C. Gel strength developed during heating of surimi in combination with egg white or whey protein concentrate. J. Food Sci. 1985, $50,1595-1597$.

9. Carlez, A.; Borderías, J.; Dumay, E.; Cheftel, J. C. High-pressure gelation of fish myofibrillar proteins. In Food Macromolecules and Colloids; Dickinson, E., Lorient, D., Eds.; Royal Society of Chemistry: Cambridge, England, 1995; pp 400-409.

10. Chung, Y. C.; Gebrehiwot, A.; Farkas, D. F.; Morrissey, M. T. Gelation of surimi by high hydrostatic pressure. J. Food Sci. 1994, 59, 523-524.

11. Davies, J. R.; Bardsley, R. G.; Ledward, D. A.; Poulter, R. G. Myosin thermal stability in fish muscle. J. Sci. Food Agric. 1988, 45, 61-68.

12. Davies, J. R.; Ledward, D. A.; Bardsley, R. G.; Poulter, R. G. Species dependence of fish myosin stability to heat and frozen storage. Int. J. Food Sci. Technol. 1994, 29, 287-301.

13. Fernández-Martín, F.; Fernández, P.; Carballo, J.; Jiménez Colmenero, F. Pressure/heat combinations on pork meat batters: protein thermal behavior and product rheological properties. J. Agric. Food Chem. 1997, 45, 4440-4445. 
14. Gilleland, G. M.; Lanier, T. C.; Hamann, D. D. Covalent bonding in pressure-induced fish protein gels. J. Food Sci. 1997, 62, 713-716, 733.

15. Hastings, R. J.; Rodger, G. W.; Park, R.; Matthews, A. D.; Anderson, E. M. Differential scanning calorimetry of fish muscle: the effect of processing and species variation. J. Food Sci. $1985,50,503-506,510$.

16. Hermansson, A. M.; Harbitz, O.; Langton, M. Formation of two different types of gels from bovine myosin. J. Sci. Food Agric.1986, 37, 69-84.

17. Howell, B. K.; Matthews, A. D.; Donnelly, A. P. Thermal stability of fish myofibrils: a differential scanning calorimetry study. Int. J. Food Sci. Technol. 1991, 26, 283-295.

18. Ikeuchi, Y.; Tanji, H.; Kim, K.; Suzuki, A. Mechanism of heat-induced gelation of pressurized actomyosin: pressure-induced changes in actin and myosin in actomyosin. J. Agric. Food Chem. 1992, 40, 1756-1761.

19. Ironside, J. I. M.; Love, R. M. Studies on protein denaturation in frozen fish. I. Biological factors influencing the amounts of soluble and insoluble protein present in the muscle of the North Sea Cod. J. Sci. Food Agric. 1958, 9, 597-617.

20. Ishikawa, M.; Sakai, K.; Yamaguchi, T.; Rachi, S. Rheological properties of gel formed by pressure-heat treatment of various fish-surimi. In High-Pressure Sciences for Food; Hayashi, R., Ed.; San-ei Publications: Kyoto, Japan, 1991; pp 184-190.

21. Iso, S.; Mizuno, H.; Ogawa, H.; Mochizuki, Y.; Mihori, T.; Iso, N. Physico-chemical properties of pressurized carp meat. Fish. Sci. 1994, 60, 89-91.

22. King, L.; Liu, C. C.; Lee, R.-F. Pressure effects and thermal stability of myosin rods and rod minifilament: fluorescence and circular dichroism studies. Biochemistry 1994, 33, 5570-5580. 
23. Ko, W. C.; Tanaka, M.; Nagashima, Y.; Taguchi, T.; Amano, K. Effect of high-pressure treatment on the thermal gelation of sardine and Alaska pollack meat and myosin pastes. Nippon Shokuhin Kogyo Gakkaishi 1990, 37, 637-642.

24. Montero, P.; Gómez-Guillén, C. Thermal aggregation of sardine muscle proteins during processing. J. Agric. Food Chem. 1996, 44, 3625-3630.

25. Montero, P.; Pérez-Mateos, M.; Solas, T. Comparison of different gelation methods using washed sardine (Sardina pilchardus) mince: effects of temperature and pressure. J. Agric. Food Chem. 1997, 45, 4612-4618.

26. Mozhaev, V. V.; Heremans, K.; Frank, J.; Masson, P.; Balny, C. High-pressure effects on protein structure and function. Proteins 1996, 24, 81-91.

27. Niwa, E. Chemistry of surimi gelation. In Surimi Technology; Lanier, T. C., Lee, C. M., Eds.; Dekker: New York, 1992; pp 389-427.

28. Okamoto, M.; Kawamura, Y.; Hayashi, R. Application of high pressure to food processing: textural comparison of pressure- and heat-induced gels of food proteins. Agric. Biol. Chem. $1990,54,183-189$.

29. Paredi, M. E.; Tomas, M. C.; Crupkin, M.; Añon, M. C. Thermal denaturation of Aulacomya ater ater (Molina) myofibrillar proteins: a differential scanning calorimetric study. J. Agric. Food Chem. 1994, 42, 873-877.

30. Park, J. W.; Lanier, T. C. Scanning calorimetry behavior of tilapia myosin and actin due to processing of muscle and protein purification. J. Food Sci. 1989, 54, 49-51.

31. Pérez-Mateos, M.; Montero, P. High-pressure induced gel of sardine (Sardina pilchardus) washed mince as affected by pressure-time-temperature. J. Food Sci. 1997, 62, 1183-1188. 
32. Pérez-Mateos, M.; Lourenço, H.; Montero, P.; Borderías, J. Rheological and biochemical characteristics of high-pressure and heat-induced gels from blue whiting (Micromesistius poutassou) muscle proteins. J. Agric. Food Chem. 1997, 45, 44-49.

33. Poulter, R. G.; Ledward, D. A.; Godber, S.; Hall, G.; Rowland, B. Heat stability of fish muscle proteins. J. Food Sci. 1985, 20, 203-217.

34. Privalov, P. L. Stability of proteins. Adv. Protein Chem. 1982, 35, 31-43.

35. Roussel, H.; Cheftel, J. C. Mechanisms of gelation of sardine proteins: influence of thermal processing and of various additives on the texture and protein solubility of kamaboko gels. Int. J. Food Sci. Technol. 1990, 25, 260-280.

36. Shoji, T.; Saeki, H.; Wakameda, A.; Nonaka, M. Influence of ammonium salt on the formation of pressure-induced gel from Walleye pollack surimi. Nippon Suisan Gakkanshi 1994, 60, 101-109.

37. Sompongse W.; Itoh, Y.; Obatake, A. Responsibility of myosin rod for the dimer formation of myosin heavy chain through SS bonding during ice storage of carp actomyosin. Fish. Sci. 1996, 62, 473-477.

38. Suzuki, T. Fish and Krill Protein: Processing Technology; Applied Science Publishers: London, England, 1981; p 132.

39. Tokunaga, T.; Nishicka, F. The improvement of technology for surimi production from fatty japanese sardine. In Fatty Fish Utilization: Upgrading from Feed to Food; Proceedings of the National Technical Conference in Raleigh; Davis, N., Ed.; Sea Grant College Publication: Raleigh, NC, 1987; pp 143-158.

40. Yamamoto, K.; Miura, T.; Yasui, T. Gelation of myosin filament under hydrostatic pressure. Food Struct. 1990, 9, 269-277. 